\title{
Análise econômica da parceria Brasil - Alemanha no contexto das relações entre o Mercosul e a União Européia
}

\author{
FREDERICO LAMEGO DE TEIXEIRA SOARES*
}

\section{O declínio da cooperação para o desenvolvimento}

Ao longo de todo o século XX, desempenhou a Alemanha papel ativo no processo de desenvolvimento da economia brasileira. Nos anos vinte e trinta, registra-se a presença alemã na estruturação dos primeiros meios de transporte aéreo brasileiros, com a fundação de filiais da Lufthansa e Condor (1927), da Varig (1927) e Vasp (1934), com capitais alemães e nacionais. Na década seguinte, no início do processo de substituição de importações, a Alemanha firmou com o Brasil um conjunto de acordos de comércio, como parte da estratégia do então III Reich de se projetar na América Latina. Tais acordos se pautaram por esquemas de trocas pagas por marcos inconversíveis, com poder de compra limitado a produtos vindos da Alemanha ${ }^{1}$. Segundo a cientista Albene Menezes:

\footnotetext{
"As economias dos dois países se completavam: a Alemanha era carente dos produtos brasileiros e tinha, em uma conjuntura de corrida armamentista, suas necessidades multiplicadas. Se circunscrevia neste quadro a necessidade do Governo brasileiro de expandir o comércio exterior para escoar o excedente de produção, sobretudo de café, que não encontrava comprador internacional e que era queimado para diminuir os estoques".
}

Com efeito, o mercado sul-americano representava para a Alemanha fonte de suprimento de matérias-primas e de produtos agrícolas suplementar às importações provenientes dos países do Leste Europeu. Para o Brasil, a Alemanha 
representava alternativa natural para contrabalançar a dependência econômica dos Estados Unidos. Com a intensificação do comércio entre os dois países, a Alemanha passou a posição de principal parceiro comercial do Brasil na década de 1930, se beneficiando especialmente das vendas de algodão. Tal evolução no intercâmbio econômico-comercial se deteriora em 1940 e é oficialmente interrompida em 1942, quando o Brasil corta relações diplomáticas e comerciais com os países do Eixo e, subseqüentemente, com a declaração de guerra à Alemanha e Itália e envio de força expedicionária ao teatro europeu.

No pós-guerra, a recém criada República Federal da Alemanha - RFA tornou-se, a partir da década de 1960, a maior exportadora de capitais líquidos do mundo, além de participar ativamente da estruturação do que viria a ser a União Européia - UE. Nesse contexto, a parceria com o Brasil fazia parte da estratégia alemã de buscar fontes de suprimento de matérias-primas e produtos agrícolas, tendo em vista as restrições de acesso ao mercado do Leste Europeu, decorrentes da formação da "Cortina de Ferro". No caso do Brasil, o restabelecimento do comércio com a RFA viria, novamente, a aliviar a dependência comercial do país em relação aos Estados Unidos da América - E.U.A, ao mesmo tempo em que os investimentos alemães representavam elemento fundamental para o objetivo brasileiro de aprofundar o processo de substituição de importações que requeria a implantação de máquinas, equipamentos, material de transporte e de um setor automobilístico.

Como resultado da complementaridade de interesses, empresas alemãs como a Volkswagen e Mercedes-Benz se prepararam para instalar fábricas, em sintonia com os objetivos do governo Vargas de nacionalizar a produção automobilística do país. Tal processo se aprofunda com Juscelino Kubitschek, quando é implementada política de incentivos e isenções às empresas estrangeiras que transferissem sua fábricas para o Brasil. Nesse período, conforme sublinhou o historiador Moniz Bandeira, as companhias norte-americanas que detinham montadoras no país não mostraram interesse - até a chegada das concorrentes alemãs - em produzir veículos no Brasil ${ }^{3}$. Outra medida relevante para promover o aprofundamento do relacionamento entre os dois países foi a decisão tardia do governo brasileiro, em 1956, de decretar a restituição dos bens de empresas alemãs, confiscados durante a guerra. Isso tudo permitiu ao Brasil se tornar o segundo maior receptor de investimentos alemães no exterior, atrás apenas dos Estados Unidos, com 40\% do total enviado na década de 1960.

A parceria bilateral atingiu seu ápice nos anos setenta, época da cooperação bilateral visando a estruturação do setor energético brasileiro, em especial na produção de energia atômica para fins pacíficos, concretizada com a assinatura de acordo nuclear firmado entre Brasil e Alemanha em 1975. Segundo o diplomata Thompson-Flôres Netto, acerca do acordo nuclear firmado entre os dois países: 
"a Alemanha foi o único país a aceitar a transferência de tecnologia na abrangência desejada pelo Brasil, inclusive, logicamente, o indispensável domínio do ciclo do combustível. Para a Alemanha, tal parceria foi estratégica ao permitir acesso mais seguro a fornecimentos de urânio brasileiro, enquanto obtinha abertura a um promissor mercado para a sua indústria nuclear" ${ }^{4}$.

A partir dos anos oitenta, contudo, diminui a importância relativa do Brasil para a Alemanha com o crescente volume de investimentos alemães direcionados ao mercado asiático. Aqui, registram-se os efeitos decorrentes da crise da dívida que prejudicaram o conjunto de iniciativas do governo brasileiro, entre as quais, 0 seu programa nuclear. De igual modo, o Leste Europeu e a ex-República Democrática Alemã passaram a receber crescente fluxo de recursos a partir dos fins dessa década em razão das transformações políticas, econômicas e culturais iniciadas nesses países. Outro motivo que explica a perda de importância do país está na própria consolidação de redes de multinacionais alemãs espalhadas em todo mundo que possibilitaram a divisão de processos produtivos em escala global.

Nos anos noventa, a Alemanha perde a posição de segundo maior parceiro do Brasil no comércio bilateral para a Argentina, devido à própria evolução do Mercosul. De igual modo, a partir da segunda metade dos anos noventa, verificouse tendência de queda abrupta do fluxo de novos investimentos alemães para o país, em contraposição à crescente participação de outros países da União Européia. Durante todo o processo de privatização brasileiro, a ausência de capitais alemães foi notória em setores como o das telecomunicações e bancário. Em contraste, os Estados Unidos mantiveram-se como principais parceiros comerciais do Brasil, bem como na condição de principais investidores, participando ativamente da compra de empresas públicas nacionais.

A par disso, o presente estudo tem como objetivo central analisar os motivos do declínio da cooperação para o desenvolvimento entre os dois países para se avaliar as perspectivas para as relações econômicas bilaterais num contexto de integração regional. Com efeito, tanto a evolução do Mercosul quanto da União Européia estão modificando o relacionamento Brasil-Alemanha na medida que essa parceria estratégica passa a considerar vários aspectos relacionados às políticas comuns no âmbito dos dois blocos. Entre esses fatores, ressaltam-se os impactos da implementação de sistema monetário comum, as negociações acerca das barreiras comerciais existentes, a aproximação da Europa com o Leste Europeu, além das perspectivas de se implementar a Área de Livre Comércio das Américas - ALCA. O trabalho examina o intercâmbio comercial e de investimentos entre os dois países e entre seus respectivos blocos. Desse modo, será possível apontar indicadores que mostrem se a União Européia desempenhará papel-chave na economia brasileira, assim como representou a Alemanha no passado, atuando 
como contraponto à crescente influência dos Estados Unidos. Além disso, será possível examinar se o interesse alemão em fortalecer suas relações com o Leste Europeu afetará as relações Brasil-Alemanha com o desvio de fluxos de investimentos dirigidos àquela região.

\section{Análise de Intercâmbio Comercial}

\section{Relações bilaterais}

A mudança no perfil do saldo comercial Brasil-Alemanha constitui o fato marcante na evolução recente das relações de trocas bilaterais. Desde 1993, os saldos do comércio bilateral passaram a se mostrar negativos para o Brasil, após anos consecutivos de superávits. No que concerne ao fluxo de intercâmbio comercial (exportações e importações), a corrente de comércio Brasil-Alemanha atingiu US\$ 8,2 bilhões em 1998, tendo as importações alcançado US \$ 5,2 bilhões e as exportações US\$3,0 bilhões, resultando em déficit comercial para o Brasil de US\$ 2,2 bilhões em relação ao pequeno superávit de US\$ 173 milhões de 1992, conforme apresentado na tabela 1 :

Tabela 1

Fluxo de Comércio Brasil-Alemanha 1992-1998 US\$ milhões - FOB

\begin{tabular}{c|c|c|c|c}
\hline Anos & Exp. Total & Imp. Total & Exp+Imp & Saldo Comercial \\
\hline 1992 & 2.063 & 1.890 & 3.953 & 173 \\
1993 & 1.808 & 2.242 & 4.050 & -434 \\
1994 & 2.049 & 3.391 & 5.440 & -1.342 \\
1995 & 2.158 & 4.794 & 6.952 & -2.636 \\
1996 & 2.083 & 4.777 & 6.860 & -2.694 \\
1997 & 2.608 & 5.132 & 7.740 & -2.524 \\
1998 & 3.006 & 5.239 & 8.245 & -2.233 \\
\hline
\end{tabular}

Fonte: Secretária de Comércio Exterior, www.mdic.gov.br, maio/2000.

No período 1992-1998, houve aumento contínuo do volume de comércio transacionado entre os dois países, devido ao crescimento das importações provenientes da Alemanha e a falta de incremento das exportações brasileiras para compensar o déficit. A reversão dos resultados da balança comercial BrasilAlemanha reflete de forma significativa o conjunto de transformações econômicas 
que se seguiram à implementação do Plano Real. Entre estas, destacam-se a conjugação de um menor nível de proteção vigente advindo da abertura comercial, a valorização da taxa de câmbio real até 1999 e a expansão da atividade econômica durante o período 1994-97. As taxas de crescimento dos valores importados mostraram-se particularmente intensas no período 1993-1997, quando totalizaram US\$ 5,2 bilhões em 1998.

A pauta de importações brasileiras de origem alemã é composta por produtos industrializados, com predominância de produtos manufaturados de alto valor agregado, entre os quais autopeças, veículos automotores, máquinas e equipamentos. Em 1997, o item partes e acessórios foi o principal produto da pauta de importação brasileira (US\$ 141,5 milhões em 1997, representando 2,76\% do total importado ${ }^{5}$ ), seguido das importações de automóveis para até 6 passageiros (US\$ 122,2 milhões em 1997, representando 2,76\% do total importado ${ }^{6}$ ). Segundo estudo da Confederação Nacional da Indústria ${ }^{7}$, o perfil da exportação brasileira para a Alemanha registra uma crescente participação de produtos manufaturados no total das exportações. A participação média anual dessa categoria de produtos elevou-se de 35,5 \% ao longo dos anos oitenta para 46,2\% na média do período 1990-98. Nos anos noventa, em termos de média anual, a participação dos manufaturados foi equivalente à registrada para os produtos básicos, de 46,7\%. Enquanto a oferta de manufaturados é dispersa em muitos produtos, a categoria dos produtos básicos apresenta uma forte concentração em café em grãos, soja e minério de ferro. Esses produtos, conjuntamente, representaram cerca de 21\% do total da pauta de exportação brasileira para a Alemanha em 1993 e 1997.

As exportações brasileiras para a Alemanha têm apresentado tendência de crescimento, conforme apresentado no gráfico 1. A oscilação observada no período 1992-1996, bem como a recuperação observada a partir de 1997, evidencia que não só a taxa de câmbio, mas, sobretudo, o nível de atividade econômica alemã tem contribuído para explicar esse desempenho.

Considerados os 25 principais produtos brasileiros exportados para a Alemanha nos anos de 1993 e 1997, observa-se uma expressiva queda da participação de alguns desses produtos no total exportado para aquele mercado. Segundo o mesmo relatório da CNI, no caso do minério de ferro, na sua forma concentrada e não concentrada, cuja participação conjunta na pauta reduziu-se de 15,3\% em 1993 para 7,8,\% em 1997, tal resultado refletiu não só o nível da atividade econômica alemã, mas, igualmente, as condições da demanda doméstica brasileira. Em 1994, as importações CIF de minério de ferro da Alemanha aumentaram 23,3\%, enquanto as exportações brasileiras do produto destinadas ao mercado alemão aumentaram 3,8\%, o que pode ser creditado à expansão da atividade pós-Real e a conseqüente redução do excedente exportável ${ }^{8}$. Em 1995, o crescimento das exportações brasileiras de minério de ferro destinadas à Alemanha voltou a superar o crescimento do total importado do produto pelo mercado alemão, refletindo em 


\section{Gráfico 1}

\section{Evolução das Exportações para a Alemanha 1992-1998}

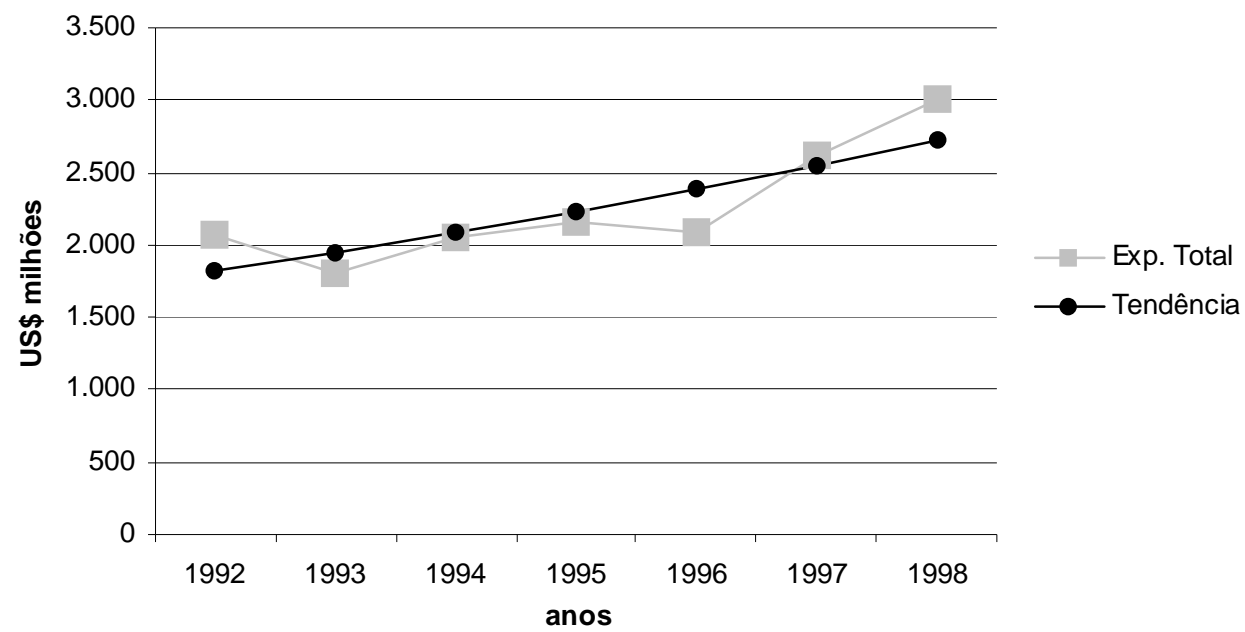

Fonte: Secretária de Comércio Exterior, ww w .mdic.gov.br, maio/2000.

aumento do excedente exportável do produto no mercado brasileiro, resultante das medidas adotadas para desacelerar o crescimento da atividade econômica interna.

\section{O comércio entre Brasil e União Européia}

A União Européia - UE tornou-se o mais importante parceiro econômico e comercial do Brasil, responsável por cerca de 30\% do comércio exterior e por algumas das mais importantes parcerias individuais do Brasil no mundo, como é caso das relações com a Alemanha. Em termos de comércio, o déficit comercial brasileiro com a Alemanha, isoladamente, foi superior ao déficit do país com a UE em 1998. Conforme já apresentado na tabela 1 , o déficit brasileiro alcançou valor de US $\$ 2,2$ bilhões naquele ano, em relação ao saldo comercial negativo de US\$ 2,1 bilhões com a União Européia (gráfico 2). Isso mostra, de um lado, o quão importante representa o mercado alemão para o comércio do país. Logo, é de se esperar que possíveis tendências de superávits para o Brasil no futuro estarão associadas ao desempenho das trocas comerciais com a Alemanha. De igual modo, os dados apresentados evidenciam que, por estar o déficit da balança comercial brasileira com a Alemanha sendo compensado pelo crescimento das exportações brasileiras para outros países no âmbito da União Européia, novos parceiros dentro da UE surgem como potenciais compradores de produtos brasileiros. 


\section{Gráfico 2}

\section{Relações comerciais do Brasil com a União Européia 1990-1998}

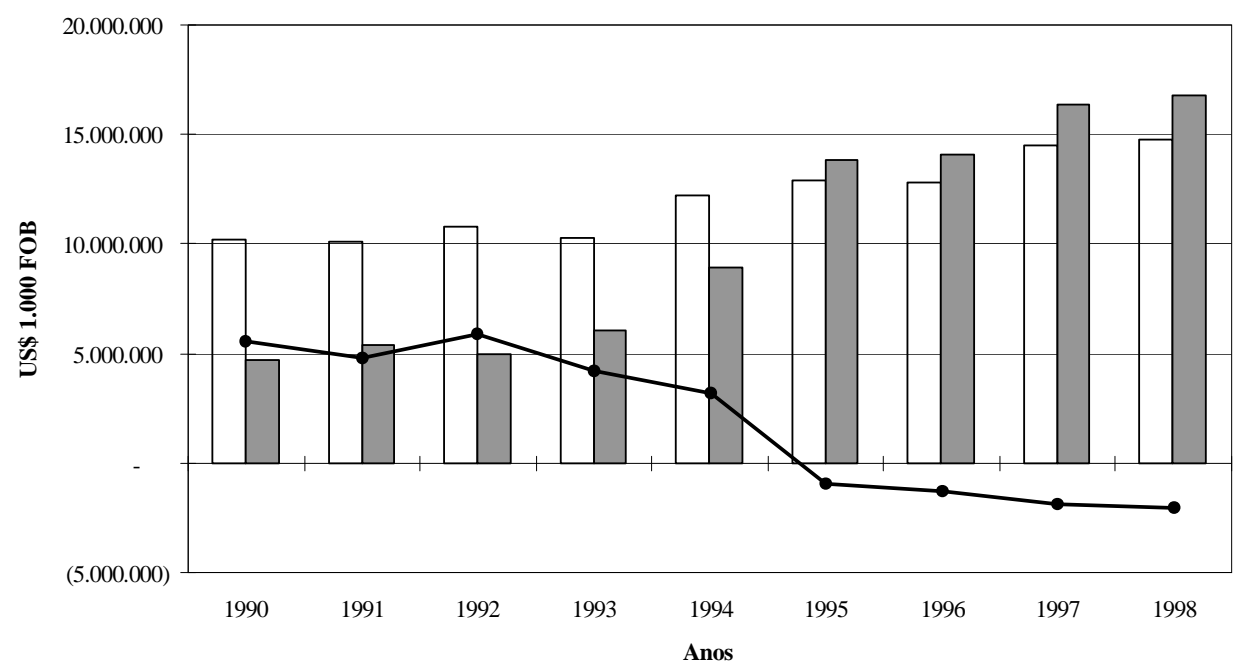

$\square$ Exportações $\square$ Importações $\longrightarrow$ Saldo Comercial

Fonte: Secretária de Comércio Exterior, www.mdic.gov.br, junho/2000.

Nesse sentido, convém notar que, pelos dados obtidos na Secretária de Comércio Exterior - SECEX ${ }^{9}$, as exportações brasileiras para o mercado europeu aumentaram de US\$ 9,9 bilhões em 1990 para cerca de US\$12,8 bilhões em 1998, representando crescimento da ordem de $30 \%$, enquanto as importações passaram de US\$ 4,7 bilhões para US\$16,8 bilhões no mesmo período, aumento de quase 360\%. No período entre 1995-1998, o intercâmbio comercial foi favorável à União Européia. Com a desvalorização do câmbio realizada no início de 1999, espera-se que haja aumento do valor exportado pelo Brasil para o mercado europeu, revertendo a trajetória de crescente déficit comercial, apesar de não ter havido crescimento nos anos anteriores à introdução do Plano Real.

De todo modo, os efeitos de uma desvalorização cambial não são suficientes para alavancar as exportações brasileiras, tendo em vista que não houve crescimento das exportações para UE no período 1990-1993 quando a taxa de câmbio era favorável ao país. A principal questão passa a estar associada ao fator competitividade, em especial, quando analisada a evolução das importações da UE. No período 1990-1998, tabela 2, países como os Tigres Asiáticos, China e da Europa Central e do Leste aumentaram suas exportações sucessivamente para a União Européia. Já os países africanos e caribenhos, signatários do Tratado de Lomé que contam com tratamento diferenciado, apresentam déficits sucessivos e 


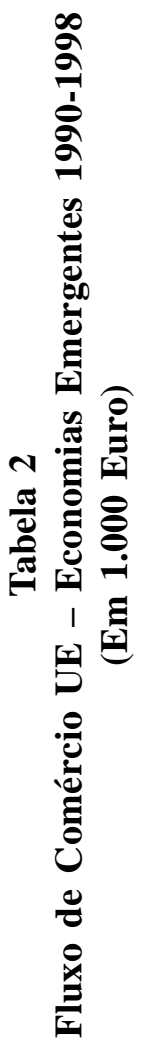

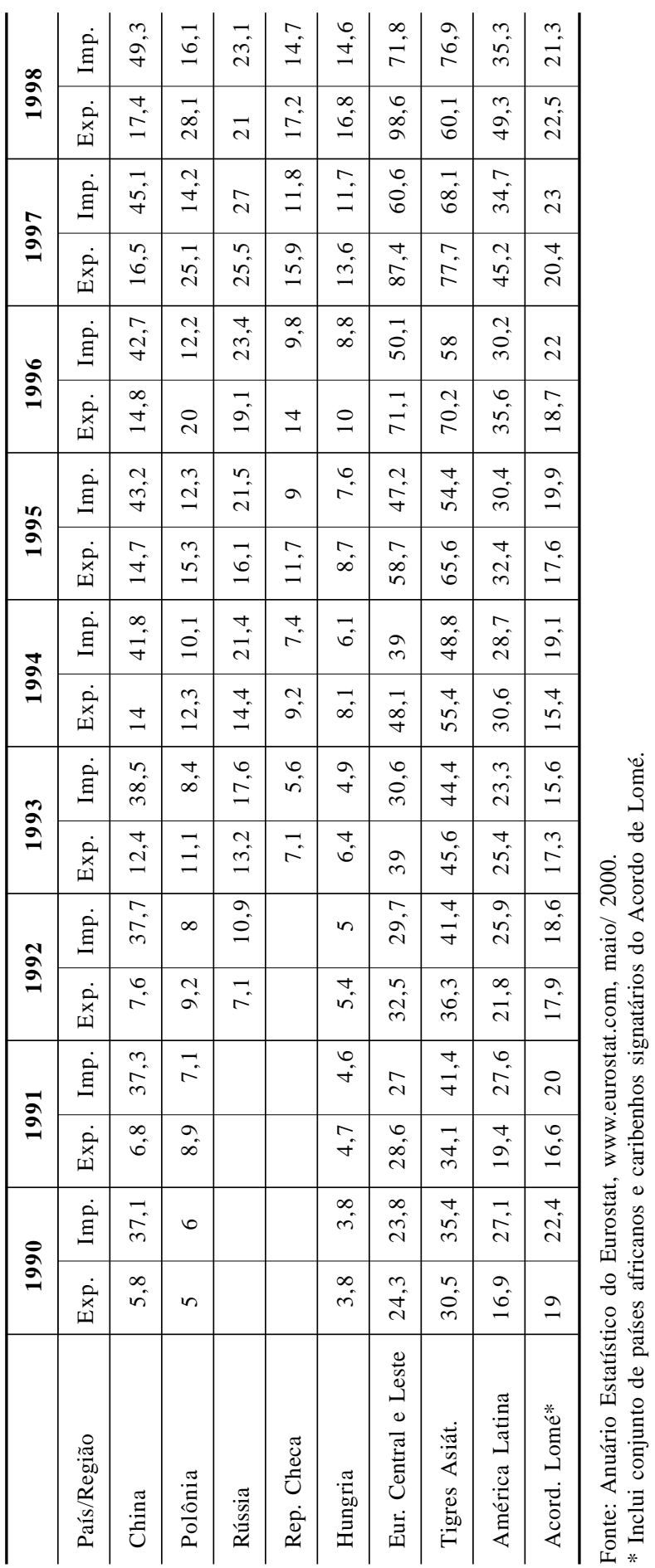


modesto crescimento nas exportações no período 1990-1998 (18\%). O desempenho da China foi exemplar já que manteve saldos comerciais positivos crescentes, combinando aumento no volume exportado. Em contraste, as demais economias emergentes que constam dessa tabela apresentaram déficit comercial com a UE, inclusive os Tigres Asiáticos (apenas em 1991 e 1998, houve superávits).

\section{Gráfico 3}

\section{Importações da UE de Economias Emergentes 1995-1998}

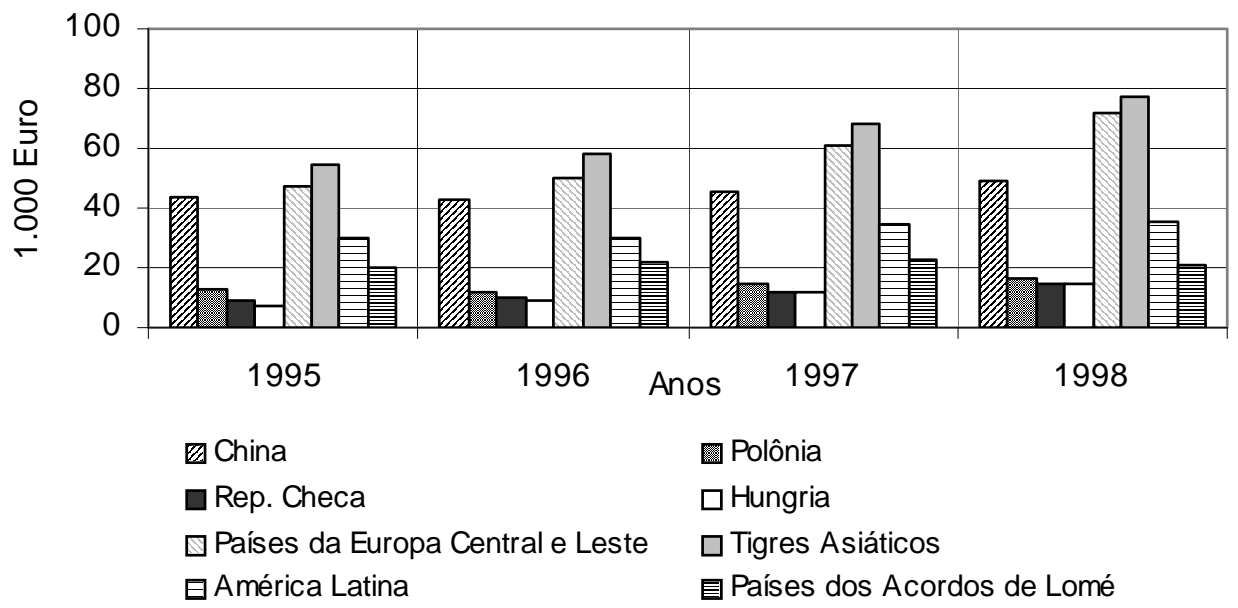

Fonte: Anuário Estatístico do Eurostat, w w w .eurostat.com, maio/ 2000.

Quando analisada a evolução das importações da Europa provenientes da América Latina, vide gráfico 3, nota-se um quadro de pouco crescimento. Em contraposição, os Tigres Asiáticos e países da Europa Central e do Leste aumentaram suas vendas de produtos à Europa. Em 1990, o Brasil exportou àquele mercado, conforme apresentado no gráfico 2, volume total de US\$ 10,2 bilhões. Nesse mesmo ano, o conjunto dos países do Leste Europeu exportou cerca de US \$ 4,8 bilhões. Já em 1998, o total exportado pelo Brasil foi de US\$ 12,8 bilhões, enquanto o das economias do Leste alcançaram cerca de US\$ 80,4 bilhões.

Vale lembrar que a adoção de medidas restritivas ao comércio pela UE vem dificultando uma maior penetração de produtos do Brasil na Europa. Nesse contexto, existem inúmeras barreiras ao comércio impostas por meio de tarifas, políticas de proteção aos produtos agrícolas (tarifação, quotas, etc), medidas sanitárias e fitossanitárias, imposição de selo ecológico ou selo verde, direitos antidumping e anti-subsídios, medidas de salvaguarda, política comercial sobre têxteis, confecções e calçados, padrões e normas técnicas, cláusulas sociais, além do Sistema Geral de Preferências comunitário (SGP). A remoção ou diminuição 
dessas barreiras é, portanto, de fundamental importância para influenciar positivamente em um melhor desempenho da pauta de produtos exportáveis, especialmente tendo em vista que parcela expressiva da pauta de exportações brasileira contempla produtos agrícolas, têxteis, minérios e semi-manufaturados, cujos mecanismos de proteção são inúmeros.

Além disso, outra dificuldade para se promover um aumento consistente das exportações brasileiras está na concorrência de outros países europeus como Portugal, Espanha e Grécia, além das ex-colônias da África, Caribe e Pacífico, os países mediterrâneos, os países da Europa Central e Oriental e África do Sul. Esses países contam com maiores facilidades de acesso ao mercado comunitário, em função de negociações de acordos preferenciais. Vale ressaltar ainda que durante a década de 1990, houve incremento acentuado das importações da União Européia provenientes de mercados concorrentes como o Leste Europeu. Esse crescimento de demanda não se refletiu, de forma proporcional, no volume exportado pelo Brasil. Apesar das exportações do Brasil para a Alemanha e para a UE terem aumentado - inclusive quando a taxa de câmbio do Real estava desfavorável -, nota-se como o Leste Europeu vem adquirindo maior participação no comércio da União Européia. Em especial, considerando o curto período de apenas oito anos em que se desenvolveu esse redirecionamento dos fluxos comerciais.

\section{Análise dos fluxos de investimentos}

O mercado brasileiro, além de absorver cerca de $70 \%$ dos investimentos diretos alemães em toda a América Latina, tornou-se o quinto mercado de destino do capital privado alemão em todo o mundo. No entanto, de acordo com dados do Banco Central do Brasil, conforme tabela 3, nota-se que no período 1996-97, o aporte de investimentos alemães ao Brasil diminuiu de forma acelerada (13,70\% em 1995, 2,77\% em 1996 para 1,28\% em 1997). Ao se avaliar a participação alemã sobre o conjunto de novos investimentos - apesar de ter havido mudança na metodologia de cálculo do Banco Central do Brasil -, houve um decréscimo acelerado em termos percentuais.

Em contraste, Estados Unidos, França e Espanha passaram a ter maior participação relativa no fluxo de investimentos para o Brasil. Um dos fatores para explicar esse crescimento está relacionado com o processo de privatização brasileiro que atraiu empresas americanas, espanholas e francesas em setores como o das telecomunicações e de energia, onde a ausência de capitais alemães, até o momento, vem sendo notória. De igual modo, está relacionado à abertura do sistema financeiro nacional que facilitou a aquisição de bancos brasileiros por grupos europeus espanhóis e portugueses. 


\section{Tabela 3}

Investimentos Diretos por País (Em US\$ milhões)

\begin{tabular}{|c|c|c|c|c|c|c|}
\hline \multirow{3}{*}{ Discriminação } & \multicolumn{6}{|c|}{ Estoque em 1995 (DEZ) } \\
\hline & \multicolumn{2}{|c|}{1995} & \multicolumn{2}{|c|}{1996} & \multicolumn{2}{|c|}{1997} \\
\hline & Valor & $\% /$ total & Valor & $\% /$ total & Valor & $\% /$ total \\
\hline Estados Unidos & $10.852,20$ & 25,52 & $1.975,40$ & 25,77 & $4.382,30$ & 28,62 \\
\hline Alemanha & $5.828,00$ & 13,70 & 212,00 & 2,77 & 195,90 & 1,28 \\
\hline Suíça & $2.815,30$ & 6,62 & 108,80 & 1,42 & 81,20 & 0,53 \\
\hline Japão & $2.658,50$ & 6,25 & 192,20 & 2,51 & 342,10 & 2,23 \\
\hline França & $2.031,50$ & 4,78 & 970,00 & 12,65 & $1.235,20$ & 8,07 \\
\hline Canadá & $1.819,00$ & 4,28 & 118,50 & 1,55 & 66,20 & 0,43 \\
\hline Reino Unido & $1.792,60$ & 4,21 & 91,50 & 1,19 & 182,50 & 1,19 \\
\hline Ilhas Virgens (Britânicas) & $1.735,60$ & 4,08 & 361,40 & 4,71 & 162,40 & 1,06 \\
\hline Países Baixos & $1.534,50$ & 3,61 & 526,80 & 6,87 & $1.487,90$ & 9,72 \\
\hline Itália & $1.258,60$ & 2,96 & 12,30 & 0,16 & 57,40 & 0,37 \\
\hline Ilhas Cayman & 891,70 & 2,10 & 655,77 & 8,55 & $3.382,90$ & 22,09 \\
\hline Uruguai & 874,10 & 2,06 & 81,20 & 1,06 & 56,10 & 0,37 \\
\hline Bermudas & 853,10 & 2,01 & 33,80 & 0,44 & 241,10 & 1,57 \\
\hline Panamá & 677,40 & 1,59 & 674,80 & 8,80 & 904,00 & 5,90 \\
\hline Suécia & 567,20 & 1,33 & 126,00 & 1,64 & 268,60 & 1,75 \\
\hline Bélgica & 558,20 & 1,31 & 111,50 & 1,45 & 135,60 & 0,89 \\
\hline Ilhas Bahamas & 509,70 & 1,20 & 74,30 & 0,97 & 300,10 & 1,96 \\
\hline Luxemburgo & 408,00 & 0,96 & 290,70 & 3,79 & 57,70 & 0,38 \\
\hline Argentina & 393,60 & 0,93 & 30,10 & 0,39 & 186,90 & 1,22 \\
\hline Espanha & 251,00 & 0,59 & 586,60 & 7,65 & 545,80 & 3,56 \\
\hline Portugal & 106,60 & 0,25 & 202,70 & 2,64 & 681,00 & 4,45 \\
\hline Coréia do Sul & 3,80 & 0,01 & 63,30 & 0,83 & 91,30 & 0,60 \\
\hline Demais & $4.109,80$ & 9,65 & 165,70 & 2,19 & 266,90 & 1,76 \\
\hline Total & $42.530,00$ & 100,00 & $7.665,37$ & 100,00 & $15.311,10$ & 100,00 \\
\hline
\end{tabular}

Fonte: FIRCE/Banco Central do Brasil, www.bcb.gov.br, maio/2000.

A participação global dos dados no montante total ingressado atingiu 73,6\% e 81,6\% em 1996 e 1997 respectivamente.

Quando avaliado o comportamento do fluxo de investimentos alemães destinado a países emergentes, gráfico 4, assinala-se como recebeu o Brasil, no mesmo período, volume superior de investimentos em comparação à Argentina, países da Europa Central e do Leste e China. No ano de 1997, conforme o Deutsche Bundesbank (Banco Central Alemão), recebeu o país volume de DM 15,9 bilhões (cerca de US\$ 9,2 bilhões). Vale lembrar que essas informações em muito contrastam com os dados obtidos no Banco Central do Brasil - BACEN, conforme apresentado acima, cujo montante foi de apenas US\$ 195,9 milhões. A metodologia de cálculo empregada pelo órgão monetário alemão contempla reinvestimentos de empresas, fundos de pensão, entre outros agregados, enquanto o banco brasileiro calcula apenas novos investimentos. Por isso, os dados para 1995 apresentam certa similaridade, ano de mudança da metodologia utilizada pelo BACEN. 


\section{Gráfico 4 \\ Investimentos Diretos da Alemanha em Economias Emergentes (1994-1997)}

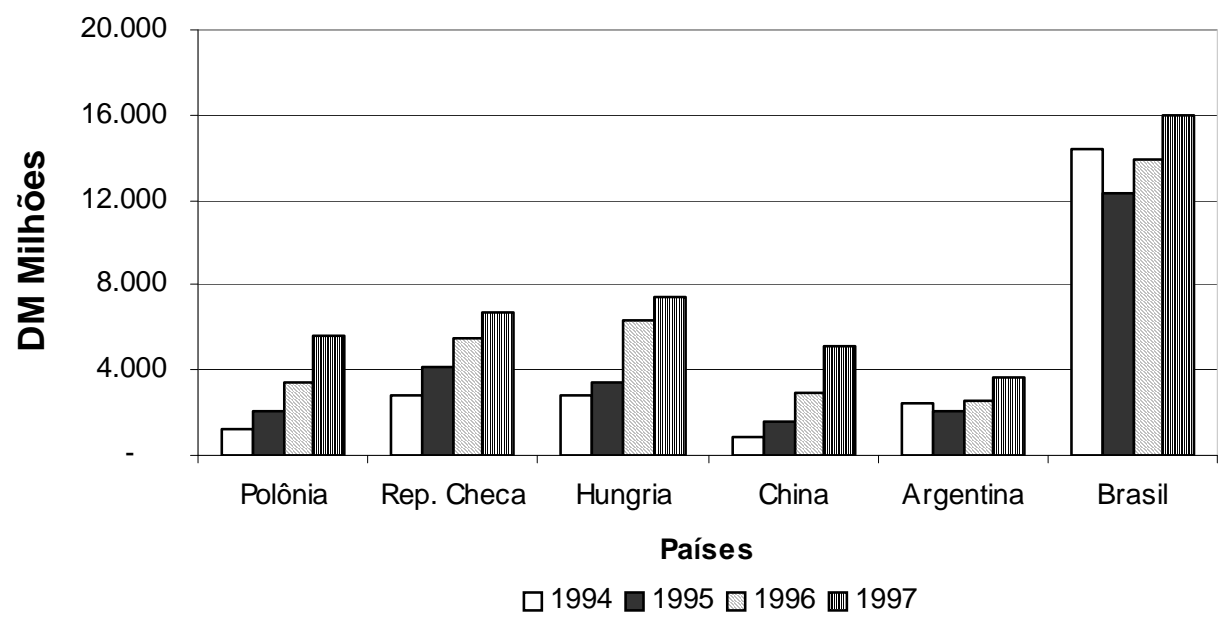

Fonte: Anuário Estatístico do Deutsche Bundesbank.

Tal fato demonstra estarem as próprias empresas alemães instaladas no Brasil reinvestindo recursos. Em junho de 1995, o volume total de reinvestimentos por parte de empresas alemãs alcançou quase US\$2,3 bilhões, enquanto o total de investimentos alemães nesse mesmo ano foi da ordem de US\$ 5,8 bilhões $^{10}$. De acordo com informações obtidas no grupo Daimler-Chrysler, os investimentos previstos e/ou já realizados no setor automobilístico na Argentina totalizam cerca US\$ 3 bilhões, enquanto no Brasil estima-se valor próximo a US\$ 10 bilhões.

Ademais, a consolidação de redes de multinacionais alemãs em todo o mundo, cujo exemplo mais recente é a fusão das empresas Daimler e Chrysler, por possibilitar integrar processos por meio da divisão da produção em vários países, prejudica um entendimento limitado a dados estatísticos. Com efeito, investimentos para financiar projetos alemães no Brasil não têm como origem única a Alemanha, já que provém tanto de filiais de empresas alemãs no exterior ou por meio de formas diversas de captação de capital. No caso do setor automobilístico, convém registrar que o total de investimentos iniciais previstos para a produção não necessariamente ocorre no Brasil, já que, muitas vezes, os custos de aquisição de máquinas e equipamentos provenientes de outros países não são contabilizados nos investimentos divulgados pelo Banco Central do Brasil. 
Contudo, o total agregado investido na Polônia, República Checa e Hungria foi superior ao enviado ao Brasil a partir de 1996. Nesse ano, esses três países receberam DM 15,3 bilhões (cerca de US\$ 9,9 bilhões), enquanto o Brasil teve aporte de DM 13,8 bilhões (US \$ 9,1 bilhões). Já no ano de 1997, as três economias da Europa Central e do Leste absorveram DM 19,7 bilhões (aproximadamente US\$11,4 bilhões), enquanto foram investidos no Brasil montante de DM 15,9 bilhões (US $\$ 9,2$ bilhões), quase o mesmo montante em dólares enviados no ano anterior. Se considerado que, pelas informações obtidas no Banco Central do Brasil, o aporte de novos investimentos para o país foi de apenas US\$ 195,9 milhões, em contraposição com a tendência de crescimento de fluxos destinados para o Leste no período 1994-1997, nota-se como o Leste Europeu vem se tornando cada vez mais relevante para a Alemanha. Outras economias, como a chinesa e a própria argentina vêm assumindo importância, mas se examinado o tamanho dessas economias em relação às três européias, verifica-se o quão estratégico se tornou o Leste Europeu para a Alemanha, após o fim da Guerra Fria. Assim, é de se esperar que o aumento de investimentos diretos alemães no Brasil virão na forma de reinvestimentos pelas próprias filias aqui instaladas.

Uma comparação do perfil de estoque de investimentos alemães com os de outros países investidores no Brasil aponta que o capital alemão manteve-se como o de maior vocação industrial, apresentando a mais elevada taxa de participação na indústria de transformação, conforme apresentado no gráfico 5. Os investimentos alemães destinaram-se, notadamente, aos segmentos automotivo (23,7\%), mecânico (12,2\%), de produtos médicos, farmacêuticos e veterinários (9,8\%) e para químicos básicos (7,4\%). O setor serviços ficou em segundo lugar com 8\% distribuídos entre os setores bancários (3\%), diversos (2,9\%) e de consultorias, representação e administração de bens (2,1\%). Os recursos em portfólio não se mostraram significativos, ao contrário do observado com outros países investidores como os Estados Unidos e Reino Unido, cujos investimentos em portfólio aumentaram de forma expressiva, em detrimento dos capitais direcionados à indústria de transformação.

No que tange os investimentos diretos da União Européia, registra-se o envio de volume de capitais de cerca 172,2 bilhões de euros (US\$ 194,4 bilhões) em 1997, conforme tabela 4. Desse total, cerca de 72,8 bilhões de euros (US\$ 82,3 bilhões) foram alocados no âmbito da própria UE. Outros 91 bilhões de euros (US\$ 102,3 bilhões) foram direcionados para fora do mercado europeu e, desse valor, 37,6 bilhões de euros (US\$ 42,5 bilhões) nos Estados Unidos, isto é 41\% do total investido fora do mercado comunitário, seguido do Japão. Nesse ano, o principal exportador de capitais foi o Reino Unido com valor de 51,5 bilhões de euros (US\$ 58,2 bilhões), seguido da Alemanha com 29,3 bilhões de euros (US\$ 33,1 bilhões) e França com 28,1 bilhões de euros (US\$ 31,7 bilhões). 


\section{Gráfico 5 \\ Investimentos e Reinvestimentos Alemães no Brasil por Ramo de Atividade 1995*}

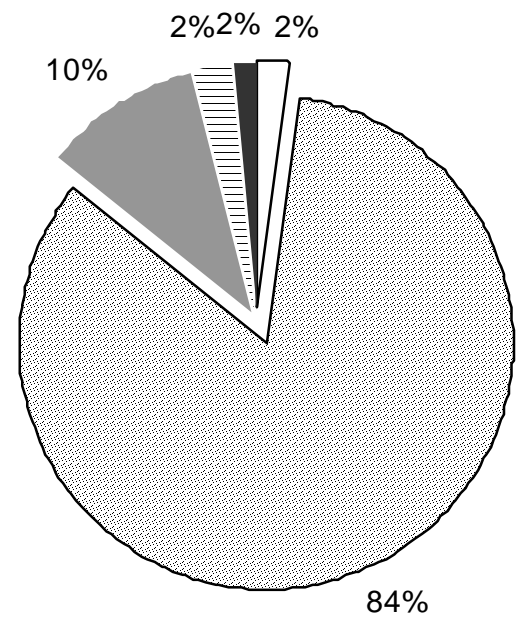

$\square$ Ind. extrativa mineral

Ind. de transformação

- Outros serviços

至 Portfólio

- Outras atividades**

* posição em 30/06/1995.

** Inclui pecuária, agricultura, pesca, serviços de utilidade pública, entre outras.

Fonte: Banco Central do Brasil, w w w .bcb.gov.br, maio/2000.

Tabela 4

Investimentos Externos Diretos da UE em 1997 (milhões de euros)

\begin{tabular}{l|r|r|r|r|r}
\hline & Mundo & \multicolumn{1}{|c|}{ UE } & Extra-UE & E.U.A & Japão \\
\hline Bélgica/Luxemburgo & 5.919 & 4.967 & 951 & -708 & -54 \\
Dinamarca & 3.712 & 2.465 & 1.248 & 235 & 15 \\
Alemanha & 29.276 & 11.411 & 14.811 & 6.382 & -172 \\
Grécia & - & - & - & - & - \\
Espanha & 8.953 & 2.553 & 6.400 & 856 & 13 \\
França & 28.139 & 12.693 & 13.795 & 6.758 & 49 \\
Irlanda & - & - & - & - & - \\
Itália & 9.373 & 5.667 & 3.704 & 253 & 979 \\
Holanda & 18.120 & 10.097 & 8.026 & 754 & 135 \\
Áustria & 1.280 & 368 & 912 & 21 & 2 \\
Portugal & 1.462 & 718 & 744 & 33 & - \\
Finlândia & 3.891 & 2.293 & 1.190 & 506 & 12 \\
Suécia & 10.039 & 810 & 5.902 & 3.946 & -26 \\
Reino Unido & 51.507 & 18.470 & 33.036 & 18.181 & 244 \\
Total UE & $\mathbf{1 7 2 . 2 7 2}$ & $\mathbf{7 2 . 8 1 4}$ & $\mathbf{9 1 . 0 1 9}$ & $\mathbf{3 7 . 5 7 5}$ & $\mathbf{1 . 2 1 6}$ \\
\hline
\end{tabular}

Fonte: Anuário Estatístico do Eurostat, www.eurostat.com, maio/2000. 
Em 1995, o total de investimentos diretos alocados no Mercosul alcançou 24,1 bilhões de euros (US \$ 31,6 bilhões), tabela 5, enquanto os países que compõe a ASEAN receberam 20,58 bilhões de euros (US\$26,9 bilhões) e a Europa e do Leste receberam 14,75 bilhões de euros (US\$ 19,3 bilhões). Tais valores comprovam como o Mercosul em 1995 ainda se apresentava como mercado preferencial de destino de capitais europeus. Apesar dessa tabela não prover informações sobre a participação alemã no total de recursos enviados para o Cone Sul, destacam-se a participação da França com volume de 4,13 bilhões de euros (cerca de US\$ 5,4 bilhões), seguido da Inglaterra com 3,57 bilhões de euros (US\$ 4,7 bilhões). Essas informações estão em consonância com a tabela 3 que mostra como outros países europeus destinaram volumes expressivos de capital para o Brasil. Novamente, os recursos destinaram-se para os processos de privatização da Argentina e Brasil em que houve grande interesse de empresas francesas e espanholas, bem como para a expansão da indústria automobilística na região.

\section{Tabela 5}

Investimentos Diretos da UE em Mercados Emergentes 1995 (bilhões de euros)

\begin{tabular}{l|c|c|c|c}
\hline País/Bloco & $\begin{array}{c}\text { Países da Europa } \\
\text { Central e do Leste* }\end{array}$ & $\begin{array}{c}\text { Sudeste } \\
\text { Asiático** }\end{array}$ & Mercosul & ASEAN*** \\
\hline Dinamarca & 0,36 & 0,48 & - & 0,57 \\
Alemanha & 5,43 & 0,97 & - & 2,76 \\
França & 1,18 & 0,16 & 4,13 & 1,27 \\
Holanda & 1,25 & 2,19 & 2,69 & 4,20 \\
Áustria & 2,53 & 0,01 & - & 0,05 \\
Finlândia & 0,07 & 0,04 & 0,09 & 0,09 \\
Reino Unido & 0,60 & 3,59 & 3,57 & 10,52 \\
União Européia & 14,75 & 8,03 & 24,10 & 20,58 \\
\hline
\end{tabular}

* Albânia, Bulgária, República Checa, Estônia, Letônia, Hungria, Lituânia, Polônia, Eslováquia e Eslovênia.

** Malásia, Tailândia e Filipinas

*** Malásia, Tailândia, Filipinas, Singapura, Indonésia, Brunei e Vietnã

Fonte: Anuário Estatístico do Eurostat, www.eurostat.com, maio/2000.

Pelos dados acima apresentados, vale notar ainda que, do total investido no Leste Europeu, cerca de 37\% dos recursos veio da Alemanha, o que comprova novamente o interesse desse país em se aproximar desse mercado. Do total de recursos enviados pela União Européia para os países que compõem a ASEAN, há uma predominância de capitais ingleses. Tal fato mostra que parcela dos investimentos externos do Reino Unido teve como principal destino a Ásia. De todo modo, destinou o Reino Unido volume expressivo de recursos para o Mercosul 
que alcançaram 3,57 bilhões de euros (US\$ 4,7 bilhões). Comparando essa informação com o que consta da tabela III, em que havia do Reino Unido estoque de investimentos no Brasil da ordem de US\$1,8 bilhões no ano de 1995-, nota-se que parcela expressiva desses recursos para o Mercosul destinaram-se ao Brasil (38,9\%).

\section{As Perspectivas para a Cooperação Brasil-Alemanha}

À luz do exposto, a parceria Brasil-Alemanha alcançou novo estágio no que tange o relacionamento bilateral. No que concerne o intercâmbio comercial apesar de ter sido desfavorável para o Brasil a partir de 1993 -, houve crescimento das exportações brasileiras para a Alemanha. Isso demonstra que há interesse dos setores empresariais de ambos os países em ampliar negócios. Com a desvalorização do Real, há ainda a possibilidade de que haja aumento das exportações. Contudo, esse desempenho, conforme já mencionado, dependerá de medidas que visem ampliar a competitividade dos produtos nacionais por meio da redução do chamado "custo Brasil”, além da resolução dos inúmeros entraves comerciais existentes.

Ações visando melhorar as condições de acesso ao mercado alemão e identificar produtos/setores com potencial para ampliar as exportações brasileiras podem contribuir para o objetivo de incrementar as exportações brasileiras para a Alemanha. A agroindústria brasileira apresenta, por exemplo, boas condições para contribuir de maneira efetiva para um maior equilíbrio nas relações comerciais entre os dois países, por ser um dos setores em que detém o Brasil grandes vantagens comparativas.

Nesse contexto, frutas e sucos tropicais são produtos em que há um significativo potencial de exportação. As frutas brasileiras devem buscar um nicho de mercado por meio do fornecimento sazonal, uma vez que a safra brasileira não coincide com a de outros fornecedores concorrentes de mercadorias similares. Contudo, apesar de ser o maior produtor mundial de frutas, de acordo com dados da $\mathrm{FAO}^{11}$, detém o país participação de menos de $1 \%$ do mercado mundial. O governo brasileiro vem promovendo esforço nos últimos anos para impulsionar a produção de frutas tropicais na região do semi-árido nordestino. Foi implementado programa de apoio ao desenvolvimento da fruticultura irrigada que objetiva ampliar a competitividade do setor por meio de conjunto de ações, entre as quais as atividades de promoção e marketing, financiamento, projetos de pesquisa e desenvolvimento tecnológico, além da formulação de projetos de defesa fitossanitária. Entre os resultados práticos que vêm se traduzindo no aumento da produção, registra-se a abertura de representações de traders alemãs na região.

Outro setor com potencial é o de máquinas e equipamentos em que as fusões e aquisições de fábricas brasileiras por empresas alemãs devem proporcionar 
um aumento de transações nos setores mecânico e eletroeletrônico cujos resultados podem ser troca de tecnologia ou lançamento de novos produtos, a partir de plantas industriais brasileiras. Na cadeia automobilística, as perspectivas são igualmente favoráveis. As montadoras alemãs vêm ampliando suas instalações no Brasil que servirão de plataformas de exportação para a América Latina. O grupo Volkswagen/ Audi inaugurou recentemente novas fábricas. No Paraná, a fábrica da Audi/VW possui capacidade instalada para a produção de 130.000/ano, onde foram investidos total de US\$ 750 milhões. Na nova fábrica do grupo no Estado do Rio de Janeiro, foram alocados US\$ 250 milhões para a produção de ônibus e caminhões.

Já a empresa Daimler-Chrysler iniciou no Brasil trabalho de alinhamento das políticas e práticas de atuação no mercado das fábricas da Mercedes-Benz e Chrysler. A Mercedes que, tradicionalmente vem atuando no mercado na produção de veículos pesados, abriu montadora na cidade de Juiz de Fora, Minas Gerais, para produzir o modelo de passeio Classe A, cujo investimento totalizou US\$ 820 milhões. A Chrysler inaugurou, igualmente, fábrica no Estado do Paraná para produzir o modelo Dakota com capacidade para 40.000/ano.

Em conseqüência, podem surgir oportunidades para os setores de autopeças via joint-ventures com essas empresas alemãs, incluindo acordos fechados de fornecimento. Em especial, tendo em vista a desvalorização cambial que impactou diretamente nas estratégias de produção dessas empresas. Houve aumento dos custos de importação de componentes de produção desses automóveis que se refletiram em custos de venda elevados, tornando-os pouco competitivos. A fábrica de Juiz de Fora do grupo Daimler-Chrysler, por exemplo, enfrenta dificuldades para atingir o nível de produção e de vendas inicialmente previsto para o modelo Classe A. Essas empresas vêm buscando a nacionalização de peças o que poderá resultar em transferência de tecnologia e de know-how para as nacionais que atuam nesse setor.

De todo modo, a entrada em vigor do Tratado de Maastricht reatualizou a questão das relações comerciais entre o Brasil e a Europa. Se no início, o principal problema consistiu em avaliar as conseqüências da união aduaneira comunitária européia para o comércio brasileiro com a busca de medidas para se diminuir o impacto negativo do protecionismo agrícola comunitário sobre as exportações do Mercosul, posteriormente, o eixo das discussões passou a estar centrado no impacto do Mercado Único Europeu. Trata-se de avaliar as transformações que a união política e financeira européia introduzirão nas relações entre Mercosul e a União Européia, seu significado e conseqüências para as relações bilaterais do Brasil com os países integrantes daquele bloco, em especial com a própria Alemanha.

Com efeito, há expectativa de que, a partir de 2002, o Euro se torne alternativa para o Dólar, quando começam a circular notas e moedas. Por esse motivo, sua implementação começa a ser amplamente analisada sob seus aspectos políticos. E, nesse caso, o Euro poderá se transformar na segunda moeda de 
referência mundial e, por conseqüência, facilitará à Europa unificar instituições ou políticas comuns a fim de transformar a sua riqueza em poder. Nesse cenário, a hegemonia dos Estados Unidos poderá ser contestada. Ao se considerar que todas as previsões pessimistas sobre a implantação do Euro no mercado comunitário não se confirmaram até o presente, é de se esperar que o Euro se torne, de fato, moeda de referência mundial, em especial a partir de 2002 com a entrada de notas e moedas no sistema bancário e financeiro europeu. Além de integrar em um único mercado todas as operações financeiras, o Euro deverá diminuir os custos das transações intra-européias, bem como fomentar maior estabilidade das economias envolvidas. Talvez seja esse um dos benefícios para os exportadores brasileiros na medida em que facilita a operacionalização de transações comerciais.

Os efeitos da introdução do Euro nas relações econômicas com o Brasil são enormes. A produção do conjunto de países da União Européia corresponde a 38\% do PIB dos principais países industrializados, além de representar cerca de $1 /$ 3 do comércio mundial. À medida que as transações externas passarem a ser denominadas na nova moeda, o Euro poderá se tornar em novo padrão de troca, assumindo papel de destaque como reserva internacional na contabilidade dos Bancos Centrais de países que comercializam com as nações européias. Para o Brasil, o grande desafio estará em aumentar as exportações para a Europa, considerando os vários entraves existentes e quando há uma tendência de desvalorização do Euro em relação a outras moedas. Com o aumento do volume de mercadorias negociado em euros, há ainda o risco de incremento das importações do Brasil de produtos provenientes da União Européia. Tal fato é ainda mais grave quando levado em consideração que manteve a UE saldos superavitários contínuos nas trocas comerciais com o Brasil nos últimos anos.

No que tange o comportamento do fluxo de capitais estrangeiros para o Brasil, a queda de novos investimentos alemães no Brasil registrada pelo Banco Central do Brasil, em contraposição com as informações divulgadas pelo Deutsche Bundesbank, demonstra estar o conjunto de empresas alemãs reinvestindo no Brasil, o que revela o grau de amadurecimento alcançado por essa parceria. As previsões de investimento do setor automobilístico são emblemáticas nesse sentido. Contudo, apesar dos recursos que incluem investimentos e reinvestimentos ao Brasil entre 1994-1997 terem sido expressivos, os mesmos dados do Deutsche Bundesbank revelam que volume de capitais superior foi destinado em 1997 para a Polônia, República Checa e Hungria em conjunto, países cujos PIB somados não alcançam o do Brasil.

Por conseguinte, é de se esperar que a participação de investimentos alemães sob o crescente fluxo de novos investimentos destinados ao Brasil se mantenha no patamar atual, já que há tendência de crescimento dos investimentos alemães para o Leste, em especial, com a conclusão do processo de integração 
das duas Alemanhas e, na medida que seja bem concluída a transição dos países da Europa Central e do Leste para regimes democráticos. Tal fato é mais grave quando considerado que os investimentos diretos americanos para o Brasil continuaram aumentando, segundo os dados do Banco Central do Brasil.

Dadas essas questões, as relações entre o Brasil e a Alemanha tornaram imprescindível novo ordenamento dos mecanismos de consulta e de cooperação. O aprofundamento do processo de integração da UE e do Mercosul reduziu a margem de negociação de ambos os países no estabelecimento de acordos bilaterais. A tomada de decisão passou a considerar políticas comuns, formuladas a partir da busca de consensos ${ }^{12}$. Por esse entendimento, o fortalecimento das relações teutobrasileiros dependerá do grau de influência que exerce cada país no âmbito do seu respectivo bloco econômico.

As opções para o Brasil resgatar seu intercâmbio com a Alemanha passaram, portanto, a estar diretamente associadas às perspectivas de se viabilizar o arranjo comercial entre o Mercosul e União Européia que ora se encontra em fase de negociação. Nesse sentido, sua viabilização apresenta inúmeros desafios. Entre os quais, registra-se a ausência de algum aparato institucional do Mercosul que atue com legitimidade política em articulações com terceiros blocos. De igual modo, vale registrar a assimetria de poder existente entre os países-membros do Mercosul e da União Européia. Há ainda a crise interna entre Argentina e Brasil, em função dos efeitos da desvalorização cambial implementada pelo segundo em 1999, que impôs questionamentos sobre o futuro do Mercado Comum do Sul. Outro fator está na própria pauta de exportações da região em que há predominância de produtos agrícolas que concorrem com terceiros países e que contam com acordos preferenciais. Nesse caso, a situação da Argentina ainda é mais crítica, tendo em vista o modelo de estabilidade adotado com base na paridade cambial. Finalmente, constam os efeitos negativos do Euro e os riscos de transformar a região do Cone Sul em importadora líquida de produtos europeus, haja vista a tendência de acúmulos de déficits comerciais do Brasil com a UE.

De todo modo, vale lembrar que as perspectivas para se chegar a um entendimento com a União Européia dependerão do próprio ritmo das discussões envolvendo a criação da Área de Livre Comércio das Américas - ALCA. Assinalase ainda que essas propostas de liberalização comercial surgiram em decorrência do próprio êxito alcançado pelo Mercosul num período de apenas nove anos, desde a assinatura do Tratado de Assunção. De igual modo, o conjunto de reformas implementado nas economias dos países do Cone Sul tornaram a região um mercado atrativo para investimentos. Tal fato é comprovado por ter o Cone Sul recebido o maior percentual do total de recursos destinados pela União Européia para economias emergentes em 1995, situação que se confirmou nos anos seguintes com o crescente fluxo de investimentos para os processos de privatizações desenvolvidos no Brasil e Argentina. 
Assim, há grandes possibilidades do Mercosul operacionalizar acordos comerciais, seja com a ALCA e/ou com a União Européia, na medida que resolva seus problemas internos e saiba agir como "figura política” no âmbito multilateral. Para tanto, é de fundamental relevância que haja por parte dos países do Mercosul um mínimo de paralelismo nas negociações comerciais em relação à ALCA e à União Européia, assim como a não existência de vínculos preferenciais a um único bloco comercial durante esse processo. Independente da retomada de relações com Leste Europeu pela Alemanha, a formatação de um acordo comum entre os dois blocos abre novas alternativas de investimento para o capital alemão. Nesse cenário, detém as empresas alemãs vantagens comparativas em relação a outros países europeus, tendo em vista a presença histórica no país.

Outubro de 2000

\section{Notas}

1 Para mais informações sobre o assunto, sugere-se Setenta e Seis Anos de Minha Vida, de Hjalmar Schlacht, presidente do Banco Central Alemão e Ministro da Economia durante a República de Weimar e o III Reich.

2 MENEZES, Albene Miriam F. “Alemanha e Brasil: o comércio de compensação nos anos 30” Em: BRANCATO, Sandra Maria Lubisco \& MENEZES, Albene Miriam F. (orgs.). Anais do simpósio cone sul no contexto internacional. Porto Alegre: EDIPUCRS, 1995. MONIZ BANDEIRA, Luiz Alberto. O milagre alemão e o desenvolvimento do Brasil. São Paulo, Editora Ensaio, 1994, pág. 80-83.

4 THOMPSON FLÔRES NETTO, Francisco. "Relações Brasil-Alemanha”. Em: FONSECA JÚNIOR, Gelson \& CASTRO, Sérgio Henrique Nabuco de. Temas de política externa brasileira II. Brasília: IPRI; São Paulo, Paz e Terra, 1994, v., p. 103-115.

5 Secretária de Comércio Exterior, www.mdic.gov.br, maio/2000.

6 Idem.

7 CNI, Relações econômicas Brasil-Alemanha, Brasília, DF, 1998

8 Dados obtidos na Secretária de Comércio Exterior - SECEX, www.mdic.gov.br.

9 Os dados para 1990, 1991, 1992 e 1993 incluem a soma dos valores de comércio registrados para a então Comunidade Econômica Européia - CEE e para Associação Européia de Livre Comércio - AELC (sem incluir a Suíça).

10 Banco Central do Brasil, www.bcb.gov.br, maio/2000.

11 Trade Yearbook, 1996.

12 Sobre o assunto ver MILWARD, Alan. The frontier of national sovereignty, history and theory, 1945-1992. Londres, Routledge, 1993.

\section{Bibliografia}

BESSA, Antônio Guimarães. “Mercosul: Relações intra-regionais”. Comércio exterior em perspectiva. CNI - Confederação Nacional da Indústria. Economia brasileira: desempenho e perspectivas, BrasíliaDF, 1999. . Rio de Janeiro, v. 7, n.2, nov. 1997. 
. Relações econômicas Brasil-Alemanha. Brasília, 1998.

ECONOMIST, The. Country Report: Brazil - $4^{\circ}$ quarter 1999, London, 1999.

KATZENSTEIN, Peter. Tamed power: Germany in Europe. Ithaca: Cornell University, 1998.

LANGE, Thomas \& PUGH, Geoffrey. The economics of German unification: an introduction. Bath: Edward Elgar, 1998.

MARKOVITS, Andrei \& REICH, Simon. The German predicament: memory and power in the new Europe. Ithaca: Cornell University, 1997.

MENEZES, Albene Miriam F. “Alemanha e Brasil: o comércio de compensação nos anos 30”. Em: BRANCATO, Sandra Maria Lubisco \& MENEZES, Albene Miriam F. (org.). Anais do simpósio Cone Sul no contexto internacional. Porto Alegre: EDIPUCRS, 1995.

MILWARD, Alan S. The frontier of national sovereignty, history and theory, 1945-1992. Londres: Routledge, 1993.

MONIZ BANDEIRA, Luiz Alberto \& Pinheiro Guimarães, Samuel. (orgs.) Brasil e Alemanha: a construção do futuro - Simpósio realizado em São Paulo, 17 a 19 de agosto de 1995, Brasília: Instituto de Pesquisa de Relações Internacionais, Fundação Alexandre Gusmão, 1995. . O milagre alemão e o desenvolvimento do Brasil. São Paulo: Editora Ensaio,1994.

PEREIRA, Lia Valls. “A desvalorização do real e o Mercosul”. Conjuntura Econômica, CNI, v.53, nº, p.13-14, abr.1999.

Resumo

O presente estudo tem como objetivo central analisar os motivos do declínio da cooperação para o desenvolvimento entre o Brasil e a Alemanha e as suas perspectivas num contexto de integração regional.

\section{Abstract}

The present study aims to analyse the causes which explain the decline of cooperation for development between Brazil and Germany and its perspectives in a context of regional integration.

Palavras-chave: Brasil. Alemanha. Mercosul. União Européia. Integração econômica.

Key-words: Brazil. Germany. Mercosur. European Union. Economic Integration. 